\title{
SHORT REPORT \\ IL-8/IL-17 gene variations and the susceptibility to severe viral bronchiolitis
}

\author{
L. A. PINTO ${ }^{1,2} *$, L. A. DE AZEREDO LEITÃO ${ }^{1,2}$, M. MOCELLIN ${ }^{1,2}$, \\ P. ACOSTA ${ }^{1,3}$, M. T. CABALLERO ${ }^{1,3}$, R. LIBSTER ${ }^{1,3}$, J. E. VARGAS ${ }^{1,2}$, \\ F. POLACK ${ }^{1,3}$, T. COMARU ${ }^{1,2}$, R. T. STEIN ${ }^{1,2}$ AND A. P. DE SOUZA ${ }^{1,2}$ \\ ${ }^{1}$ Aliança INFANT Argentina-Brasil \\ ${ }^{2}$ Centro INFANT at Insitute of Biomedical Research, Pontificia Universidade Catolica do Rio Grande do Sul, \\ Porto Alegre, Brazil \\ ${ }^{3}$ Fundación INFANT, Buenos Aires, Argentina
}

Received 13 June 2016; Final revision 21 September 2016; Accepted 14 October 2016; first published online 28 November 2016

\section{SUMMARY}

Clinical manifestations of acute bronchiolitis (AB) vary from minimal disease to severe respiratory failure. The response to respiratory viral infections is possibly influenced by genetic polymorphisms linked to the regulation of the inflammatory response. In the present study, we investigated whether interleukin-8 (IL-8) and interleukin-17 (IL-17) genetic variants are associated with the severity of $\mathrm{AB}$. A group of Brazilian infants hospitalized with $\mathrm{AB}$ and a control group (infants with no or mild $\mathrm{AB}$, without hospitalization) were genotyped for four IL8/IL-17 variations. For replication, we studied an Argentinean population sample of infants with mild and severe AB. IL-8 polymorphism (rs 2227543) and IL-17 (rs2275913) variants showed significant associations with the severity of AB. The effect of the IL- 8 variation could be replicated in the Argentinean sample. This finding suggests that IL-8 variations may influence the severity of $\mathrm{AB}$ in young infants. Further genetic association studies in low- or middle-income populations are necessary with the aim of expanding knowledge in this area.

Key words: Bronchiolitis, interleukin-8, polymorphism, severity, wheezing.

Acute bronchiolitis (AB) is universally recognized as the most frequent cause of hospitalization in the first year of life. In Latin America, as in other developing regions, $\mathrm{AB}$ and wheezing also present significant morbidity and high costs to the public health system [1]. The severity of $\mathrm{AB}$ is extremely variable, and factors that influence severity are not fully established. There are different genetic and immunological factors involved in the response of each individual to

\footnotetext{
* Author for correspondence: Dr L. A. Pinto, Avenida Ipiranga, 6690, $2^{\circ}$ andar, Instituto de Pesquisas Biomédicas. CEP 90·610-000, Porto Alegre, RS, Brasil.

(Email: leonardo.pinto@pucrs.br)
}

respiratory viral infections [2]. Respiratory syncytial virus (RSV) is the most common cause of bronchiolitis in infants. Among the genetic variations associated with $\mathrm{AB}$, interleukin-8 (IL-8) polymorphisms have been shown to influence patients' response to RSV infection [3]. Moreover, interleukin-17 (IL-17) is a pro-inflammatory cytokine expressed in respiratory cells and bronchoalveolar lavage of patients with $\mathrm{AB}$ [4]. However, the role of IL-8 and IL-17 genes in $\mathrm{AB}$ is not yet fully understood and has never been investigated in low- or middle-income population samples.

The aim of the present study was to compare the frequency of genotypes of IL-8 and IL-17 
polymorphisms in infants with severe $\mathrm{AB}$ and controls recruited in a low-income area in Southern Brazil. The significant association with IL-8 was replicated in a population sample with similar socioeconomic conditions from Argentina.

This is a case-control genetic association study designed to investigate the role of IL-8 and IL-17 on severe AB. The first study sample was selected in a tertiary university hospital (Hospital São Lucas, PUCRS), in Porto Alegre, Brazil. The study included all children admitted with a diagnosis of $\mathrm{AB}$ between September 2009 and September 2011. A healthy control group without $\mathrm{AB}$ was recruited in a community primary-health centre, with the same economic and environmental backgrounds as the case group.

For replication, we used a prospective case-control study conducted in Buenos Aires, Argentina, between 2010 and 2013. Infants were recruited from hospitals caring for middle-income, insured central families (Swiss Medical Center, CEMIC, Hospital Español) in the Central region and public institutions caring for low-income families (Hospital Pedro de Elizalde and Hospital Lucio Melendez) in the Southern region. Previously healthy full-term infants aged $<2$ years with signs and symptoms of bronchiolitis for the first time were invited to participate.

To evaluate sample size, we considered the following parameters: allele frequency of $0 \cdot 37$, estimated strength of association of 2 , power of $80 \%, \alpha$-level of $0 \cdot 05$, and case-control ratio of $0 \cdot 5$. With these parameters, the total number estimated was 130 patients (by OSSE Sample Size Estimator; http://osse.bii.astar.edu.sg).

There are no known common variants in the coding sequence of IL-8. Two of the variants are located in introns (rs2227307 and rs2227543) while the remaining variant (rs4073) is found in the promoter region of IL-8 and has been shown to associate with several pulmonary phenotypes $[5,6]$ and demonstrate functional effects [5, 6].

Blood samples were stored through the FTA Classic Card at the Institute of Biomedical Research (IPB/ PUCRS). DNA was extracted according to the manufacturer's instructions (Whatman, USA). In summary, the procedure was performed using a Harris Uni-core punch $1.25 \mathrm{~mm}$ to punch a disk from the card (Whatman). The DNA extraction from the disk was performed using FTA Purification Reagent (Whatman) and Tris-EDTA (TE) for washing the sample. The material was then heated at $60{ }^{\circ} \mathrm{C}$ for $30 \mathrm{~min}$, with $20 \mu \mathrm{l}$ nuclease-free water (IDT, USA), using a thermal cycler PTC-100 (MJ Research, Canada). Subsequently, DNA quantification was performed with a Qubit DNAHS kit (Invitrogen, USA). We used $0 \cdot 1-0 \cdot 25$ ng genomic DNA in a PCR reaction volume of $10-25 \mu \mathrm{l}$, depending on the genomic DNA sample concentration. For the PCR reaction were used 0.5-0.625 $\mu \mathrm{l}$ TaqMan SNP genotyping assays, which contain primers and a specific fluorescent-dyelabelled probe for each allele (Applied Biosystems, USA), and 5-12.5 $\mu 1$ of TaqMan Genotyping Master Mix (catalogue no.: 4371 355, Applied Biosystems). The PCR amplification was analysed in a StepOne Real-Time PCR System (Applied Biosystems) using the thermocycler parameters of $50^{\circ} \mathrm{C}$ for $2 \mathrm{~min}, 95^{\circ} \mathrm{C}$ for $10 \mathrm{~min}, 95^{\circ} \mathrm{C}$ for $15 \mathrm{~s}$ and $60^{\circ} \mathrm{C}$ for $90 \mathrm{~s}$, repeating the last two cycles 50 . The result for each allele was analysed by endpoint detection of the fluorescent signals.

Three SNPs in the IL-8 gene were genotyped: rs4073 (assay ID C_11748116_10, AB), rs2227307 (assay ID C_11748168_10, AB), and rs2227543 (assay ID C_15955936_10, AB). One polymorphism in the IL-17 gene was genotyped: rs2275913 (assay ID C_15879983_10, AB). Genotype frequencies were compared by $\chi^{2}$ tests. The significance limit was $0 \cdot 05$. Statistical analysis was performed using SPSS v. 16.0 (SPSS Inc., USA).

In the Brazilian population sample, we included 121 cases and 71 controls $(n=192)$ that had DNA samples available for first association analyses. Patients with severe AB (hospitalized) had a mean age of 3.4 months. Controls were infants that completed 12 months with no or mild AB (without hospitalization). The gender distribution showed a non-significant higher frequency of males in the group of cases (56.5\%) compared to controls $(40 \cdot 0 \%)$. The genotyping success rates varied between $92 \cdot 0 \%$ and $99 \cdot 4 \%$. There were no significant deviations from HardyWeinberg equilibrium.

The minor allele of IL-8 variant rs2227543 was associated with significant protection for severe $A B$, with significantly higher frequency of the homozygous TT allele in patients in the control group (odds ratio $0 \cdot 25,95 \%$ confidence interval $0 \cdot 10-0 \cdot 65$ ). However, other IL-8 genetic variations showed no significant association with severe AB (Table 1). SNP rs2275913 of the IL-17 gene showed a protective effect for severe AB (hospitalization), with higher frequency $(14 \cdot 1 \% v s$. $5.8 \%, P=0.047$ ) of homozygous AA patients in the control group (without hospitalization). The risk of severe bronchiolitis in GG/AG patients was 2.7 times 
Table 1. Results of genotyping in the case-control association study and association between genotypes and severe bronchiolitis

\begin{tabular}{|c|c|c|c|c|c|}
\hline SNPs & Genotype & Alleles & Severe $\mathrm{AB}^{*}, n(\%)$ & Controlsł, $n(\%)$ & $P$ value \\
\hline Brazilian sample & & & $(n=121)$ & $(n=71)$ & \\
\hline \multirow[t]{2}{*}{ IL-8 rs4073 } & Homozygous/heterozygous & TT/TA & $95(78 \cdot 5)$ & $44(65 \cdot 7)$ & \\
\hline & Rare homozygous & AA & $26(21 \cdot 5)$ & $23(34 \cdot 3)$ & $0 \cdot 143$ \\
\hline \multirow[t]{2}{*}{ IL-8 rs2227307 } & Homozygous/heterozygous & GG/GT & $69(59 \cdot 5)$ & $31(51 \cdot 6)$ & \\
\hline & Rare homozygous & TT & $46(39 \cdot 7)$ & $27(43 \cdot 5)$ & $0 \cdot 782$ \\
\hline \multirow{2}{*}{ IL-8 rs2227543 } & Homozygous/heterozygous & $\mathrm{CC} / \mathrm{CT}$ & $107(92 \cdot 5)$ & $44(73 \cdot 3)$ & \\
\hline & Rare homozygous & TT & $8(6 \cdot 9)$ & $14(22 \cdot 6)$ & $<0 \cdot 001$ \\
\hline \multirow[t]{2}{*}{ IL-17 rs2275913 } & Homozygous/heterozygous & $\mathrm{GG} / \mathrm{GA}$ & $114(94 \cdot 2)$ & $61(85.9)$ & \\
\hline & Rare homozygous & AA & $7(5 \cdot 8)$ & $10(14 \cdot 1)$ & $0 \cdot 047$ \\
\hline \multirow{3}{*}{$\begin{array}{l}\text { Argentinean sample } \\
\text { IL-8 rs2227543 }\end{array}$} & & & $(n=43)$ & $(n=34)$ & \\
\hline & Homozygous/heterozygous & $\mathrm{CC} / \mathrm{CT}$ & $41(95 \cdot 4)$ & $28(82 \cdot 4)$ & \\
\hline & Rare homozygous & TT & $2(4 \cdot 6)$ & $6(17 \cdot 6)$ & 0.008 \\
\hline \multirow{3}{*}{$\begin{array}{l}\text { Pooled sample } \\
\text { IL-8 rs2227543 }\end{array}$} & & & $(n=164)$ & $(n=105)$ & \\
\hline & Homozygous/heterozygous & $\mathrm{CC} / \mathrm{CT}$ & $148(93 \cdot 7)$ & $72(78 \cdot 3)$ & \\
\hline & Rare homozygous & TT & $10(6 \cdot 3)$ & $20(21 \cdot 7)$ & $<0 \cdot 001$ \\
\hline
\end{tabular}

SNP, Single nucleotide polymorphism; IL, interleukin-8.

* AB, Acute bronchiolitis with hospitalization.

$\dagger$ Infants with no or mild bronchiolitis (without hospitalization).

$\$ \chi^{2}$ test.

higher compared to genotype AA patients. Furthermore, in a sub-analysis for SNP rs2227543, we observed trends for protection when the outcomes length of hospitalization, oxygen usage and wheezing were studied.

When rs2227543 variation was tested in a second population sample from Argentina, the effect could be replicated in infants recruited from low-income areas (Table 2). The homozygote TT genotype was four times more frequent in milder cases $(4 \% v s$. $17 \%)$. When a pooled analysis was performed, we observed the same effect in a larger sample $(n=269)$.

$\mathrm{AB}$ is a disease with different clinical manifestations that may vary from mild cough and wheezing to respiratory muscle retractions and acute respiratory insufficiency. Our study may help to understand genetic influence on the severity of $\mathrm{AB}$, considering that the effect of IL-8 and IL-17 variations may be different in diverse population samples, depending on the socioeconomic status and, probably, on lipopolysaccharide exposure.

SNP rs2275913 of the IL-17 gene showed an effect for $\mathrm{AB}$ severity (with hospital admission), with higher frequency of AA homozygotes in control patients. The risk of patients with the $\mathrm{G}$ allele for severe bronchiolitis was 2.7 times higher compared to AA patients. IL-17 levels in the airways of patients with RSV-AB increased during the course of the disease in hospitalized patients [4]. Thus, the effect of SNP rs2275913 could be explained by possible variations in IL-17 expression. However, IL-17 effect could not be replicated in a second population sample.

According to our results, the rs2227543 variation was associated with severity of $A B$ in infants, revealing significantly higher frequency of the homozygous TT alleles in patients with milder manifestations in both studied samples. Homozygous TT patients had a lower chance of being admitted for AB and, if hospitalized, they had a lower risk of staying longer in hospital.

The results of the case-control study and the evaluation of hospital stay in the $\mathrm{AB}$ group show consistent results for the effect of the $\mathrm{T}$ allele (rs2227543). Knowledge of IL-8/IL-17 genetic polymorphisms and their association with $\mathrm{AB}$ outcomes may have important clinical relevance and can address specific therapeutic strategies for high-risk patients. Recently, IL-8 has been described as a therapeutic target in bronchiolitis and recurrent wheezing in infants, and may influence the response to azithromycin [7].

Our group has previously investigated the effect of macrolides on $\mathrm{AB}$ [8]. In our study, azithromycin did not influence $\mathrm{AB}$ outcome. However, the effect of macrolides (or other interventions) in infants with recurrent wheezing or with specific genotypes may be an important strategy in the future. We have studied the effect of genetic variations in infants with recurrent wheezing or bronchitis [9]. However, only a few studies suggest an influence of genetic polymorphisms 
Table 2. IL-8 rs2227543 genotype frequencies in different population samples showing lower minor allele frequencies in populations from African ancestry

\begin{tabular}{|c|c|c|c|c|}
\hline Population ID & Total sample & Major allele frequency & Minor allele frequency & Genotype frequency \\
\hline $\begin{array}{l}\text { HapMap-CEU } \\
\text { (EU ancestry) }\end{array}$ & 226 & $C=0.59$ & $\mathrm{~T}=0 \cdot 41$ & $\begin{array}{l}\mathrm{C} / \mathrm{T}=0.460 \\
\mathrm{C} / \mathrm{C}=0.362 \\
\mathrm{~T} / \mathrm{T}=0.176\end{array}$ \\
\hline $\begin{array}{l}\text { HAPMAP-ASW } \\
\text { (African) }\end{array}$ & 98 & $\mathrm{C}=0.91$ & $\mathrm{~T}=0.09$ & $\begin{array}{l}\mathrm{C} / \mathrm{C}=0 \cdot 840 \\
\mathrm{C} / \mathrm{T}=0 \cdot 142 \\
\mathrm{~T} / \mathrm{T}=0 \cdot 020\end{array}$ \\
\hline $\begin{array}{l}\text { HAPMAP-MEX } \\
\text { (Mexican) }\end{array}$ & 100 & $C=0.69$ & $\mathrm{~T}=0 \cdot 31$ & $\begin{array}{l}\mathrm{C} / \mathrm{C}=0 \cdot 460 \\
\mathrm{C} / \mathrm{T}=0 \cdot 460 \\
\mathrm{~T} / \mathrm{T}=0 \cdot 080\end{array}$ \\
\hline $\begin{array}{l}\text { HAPMAP-LWK } \\
\text { (Kenya) }\end{array}$ & 178 & $\mathrm{C}=0.89$ & $\mathrm{~T}=0 \cdot 11$ & $\begin{array}{l}\mathrm{C} / \mathrm{C}=0.797 \\
\mathrm{C} / \mathrm{T}=0.179 \\
\mathrm{~T} / \mathrm{T}=0.022\end{array}$ \\
\hline $\begin{array}{l}\text { HapMap-YRI } \\
\text { (Nigeria) }\end{array}$ & 226 & $\mathrm{C}=0.94$ & $\mathrm{~T}=0 \cdot 06$ & $\begin{array}{l}\mathrm{C} / \mathrm{C}=0.884 \\
\mathrm{C} / \mathrm{T}=0.106 \\
\mathrm{~T} / \mathrm{T}=0.008\end{array}$ \\
\hline $\begin{array}{l}\text { HAPMAP-MKK } \\
\text { (Kenya) }\end{array}$ & 284 & $\mathrm{C}=0 \cdot 80$ & $\mathrm{~T}=0 \cdot 20$ & $\begin{array}{l}\mathrm{C} / \mathrm{C}=0.626 \\
\mathrm{C} / \mathrm{T}=0.345 \\
\mathrm{~T} / \mathrm{T}=0.028\end{array}$ \\
\hline
\end{tabular}

on the severity of $\mathrm{AB}$ in young infants from Latin America. A study performed at the Fundación INFANT, in Buenos Aires, recently showed an effect of the TLR4 polymorphism in an Argentinean sample [10]. However, IL-8 and IL-17 are important $\mathrm{AB}$ candidate genes that still require further investigation $[6,7]$.

The present study has some limitations. The sample size is not large enough to investigate IL-8 infrequent variations. However, rs2227543 is a frequent polymorphism with minor allele frequency $>0.3$ in different samples described (Table 2). Moreover, the possibility of admixture bias should be described. However, 33 ethnicity-specific genomic markers were studied in the Argentinean sample and revealed neither evidence of admixture nor significant ethnic differences between the groups [10].

$\mathrm{AB}$ and recurrent wheezing in young infants have a huge health impact in Latin America [1]. Genetic association studies in low- or middle-income countries are necessary with the aim of expanding knowledge in this area. The results of the present study suggest that the IL-8 rs2227543 polymorphism may influence the severity of bronchiolitis in young infants.

African-American and Hispanic ethnicity have been described as risk factors for severe bronchiolitis. In addition, genetic databases show that AfricanAmericans and Hispanics have lower frequency of the $\mathrm{T}$ allele (rs2227543), which could partly explain the increased risk in these populations (Table 2, data by dbSNP, NCBI).

In our study, replication was possible and was performed to confirm the association with the outcome severe bronchiolitis in more than one population, which adds significantly to the strength of the reported findings. In conclusion, the results of the present study suggest that the IL-8 rs2227543 polymorphism may influence the severity of bronchiolitis in young infants. Further genetic association studies in low- or middleincome populations are necessary with the aim of expanding knowledge in this area.

\section{ACKNOWLEDGEMENTS}

This research has been funded by Fundação de Amparo a Pesquisa do Estado do Rio Grande do Sul (FAPERGS). The sponsor did not participate in the collection, analysis, or interpretation of the data, or in the writing or decision to submit the manuscript.

\section{DECLARATION OF INTEREST}

None.

\section{REFERENCES}

1. Mallol J, et al. International prevalence of recurrent wheezing during the first year of life: variability, 
treatment patterns and use of health resources. Thorax 2010; 65: 1004-1009.

2. Ciencewicki JM, et al. A genetic model of differential susceptibility to human respiratory syncytial virus (RSV) infection. Journal of the Federation of American Societies for Experimental Biology 2014; 28: 1947-1956.

3. Hull J, Thomson A, Kwiatkowski D. Association of respiratory syncytial virus bronchiolitis with the interleukin 8 gene region in UK families. Thorax 2000; 55 : 1023-1027.

4. Faber TE, et al. Specific increase in local IL-17 production during recovery from primary RSV bronchiolitis. Journal of Medical Virology 2012; 84: 1084-1088.

5. Heinzmann A, et al. Association study suggests opposite effects of polymorphisms within IL8 on bronchial asthma and respiratory syncytial virus bronchiolitis. Journal of Allergy and Clinical Immunology 2004; 114: 671-676.

6. Hacking D, et al. Increased in vivo transcription of an IL-8 haplotype associated with respiratory syncytial virus disease-susceptibility. Genes and Immunity 2004; 5: 274-282.

7. Beigelman A, et al. Randomized trial to evaluate azithromycin's effects on serum and upper airway IL-8 levels and recurrent wheezing in infants with respiratory syncytial virus bronchiolitis. Journal of Allergy and Clinical Immunology 2015; 135: 1171-1178.

8. Pinto LA, et al. Azithromycin therapy in hospitalized infants with acute bronchiolitis is not associated with better clinical outcomes: a randomized, double-blinded, and placebo-controlled clinical trial. Journal of Pediatrics 2012; 161: 1104-1108.

9. Pinto LA, et al. Polymorphisms in the IRF-4 gene, asthma and recurrent bronchitis in children. Clinical and Experimental Allergy 2013; 43: 1152-1159.

10. Caballero MT, et al. TLR4 genotype and environmental LPS mediate RSV bronchiolitis through Th2 polarization. Journal of Clinical Investigation 2015; 125: 571-582. 